\title{
Influence of gas-dynamic parameters of the heat carrier on the efficiency of drying peas in rotary dryers with a fluidized bed
}

\author{
Roman Yakobchuk, Sviatoslav Lementar \\ National University of Food Technologies, Kyiv, Ukraine
}

Keywords:
Drying
Peas
Rotory
Dryer
Fluidization

Article history:

Received 02.09.2019

Received in revised

form 27.01.2020

Accepted 30.06.2020

\section{Corresponding}

author:

Roman Yakobchuk

E-mail:

yakroman@ukr.net

DOI: $10.24263 / 2304-$

974X-2020-9-2-15

\section{Abstract}

Introduction. The aim of the research is determination the influence of gas-dynamic parameters of heat carrier movement in the chamber of a rotary drying unit with a fluidized bed on the efficiency of the peas drying process.

Materials and methods. The research was carried out on an experimental drying unit with a conical element installed in the drying chamber, and with the help of 3D models of drying units. The simulation of the heat carrier movement was performed using CFD methods, followed by verification in a pilot plant.

Results and discussion. It is established that the heat carrier speed in the drying chamber without a conical element is in the recommended limits $(1.8-2 \mathrm{~m} / \mathrm{s})$ only in the range from 0 to 0.7 $\mathrm{m}$ in the height of the chamber. The zone from 0.7 to $1.2 \mathrm{~m}$ is used less efficiently, because the velocity of the heat carrier is in the range of $1.65-1.8 \mathrm{~m} / \mathrm{s}$. The reason for this is that when the heat carrier passes through the wet product, its temperature decreases, it leads to decreasing of heat carrier volume. This causes the destruction of the constant mode of heat carrier and consequently reducing of the intensity of drying of the product.

In the drying unit with a conical element, the stabilization of the heat carrier speed is achieved within the recommended (1.8$2 \mathrm{~m} / \mathrm{s}$ ) limits along the entire height of the drying zone, which provides a constant height of the fluidized bed of product in the drying chamber. This creates the conditions for a higher intensity of drying the material and improves the quality of the dried product, because it does not stay for a long time in the high temperature zone.

It is found out that with heat carrier speed increasing over 2 $\mathrm{m} / \mathrm{s}$ there is a decrease in the efficiency of its potential. Thus at an initial speed of $2 \mathrm{~m} / \mathrm{s}$ and an initial temperature of $100{ }^{\circ} \mathrm{C}$, its final temperature is about $55{ }^{\circ} \mathrm{C}$, which coincides with drying regulations for installations of this type. While increasing speed up to 2.2 and $2.4 \mathrm{~m} / \mathrm{s}$ there is final temperature increasing of the heat carrier up to 58 and $60{ }^{\circ} \mathrm{C}$ and as a result it reduces the efficiency of this installation.

Conclusions. This research allows to determine the influence of the installation of a conical element in the drying chamber on the speed of the of heat carrier and its pressure in the drying zone, as well as the influence of the speed of the drying agent on its temperature in this zone. 


\section{Introduction}

There are various methods of green peas drying, including drying in a fluidized bed, which has proved its effectiveness as it provides equal distribution of the heat carrier inside the layer of material and high intensity of its drying [1]. One of the most efficient drying units of this type is a rotor dryer which provides equal distribution of the drying agent in the cross section of the drying chamber and its intensive interaction with the product [2]. However it is difficult to ensure a constant height of the fluidized bed, which reduces its efficiency in this kind of dryer [2].

It is necessary to research the gas-dynamic parameters of the heat carrier in the drying chamber to solve this problem and provide recommendations for improving the design of the drying unit. It should take into account not only the highest acceptable temperature of the product, but also the rate of its achievement, i.e. the heating rate, as well as the duration of the product at this temperature $[3,4]$. In addition, the interaction of the heat carrier and the product is substantiated by design features of the drying unit [5].

In order to reduce the cost of experimental dryers and expand the range of research [6, 7], the feasibility of using CFD methods to model the process of drying products in a fluidized bed is substantiated. According to this approach, it is important to choose an appropriate calculation model and the reliability of the input data [8,9]. Taking into account the peculiarity of the research process, the authors [10] argue that while modelling it is also very important to analyze the sensitivity of the model's responses to changes in parameters in the main components of the equations to identify possible weaknesses in model prediction. For this reason in this research $[10,11]$ the influence of the following parameters was analyzed: total volumetric heat transfer coefficient, heat loss coefficient, drying rate, specific heat of solid and specific heat of dry air on the forecasting model studied in this research [12]. These data can be used to describe the functional dependencies of the input parameters that are embedded in the calculation model. It is also important to be able to scale research results. The authors of [11] proposed a method for scaling the results of studies of fluidized bed dryers using the volume coefficient of heat transfer.

The research results of $[13,14,15]$ authors mentioned above and other ones showed high reproducibility in real research facilities and in the operation of industrial equipment, but they were carried out on equipment that is structurally different from those which are considered in this article.

Therefore, the aim of the research is to determine the gas-dynamic parameters of the heat carrier movement during peas drying in the chamber of a rotary drying unit with a fluidized bed [2].

\section{Materials and methods}

The process of drying peas was researched. Preparation of research samples was carried out according to the methodology [13].

For modeling, 3D-models of rotary-type drying units with a fluidized bed without a conical element [2] and with a conical element were used (Figure 1). Inside the drying chamber with a conical element there is a perforated lattice with a sector cutout, where the drive shaft with a conical element with welded blades is placed (Figure 2). The design of the basic drying chamber [2] is different as there is no conical element. The geometrical parameters of the model are shown in Figure 3. 

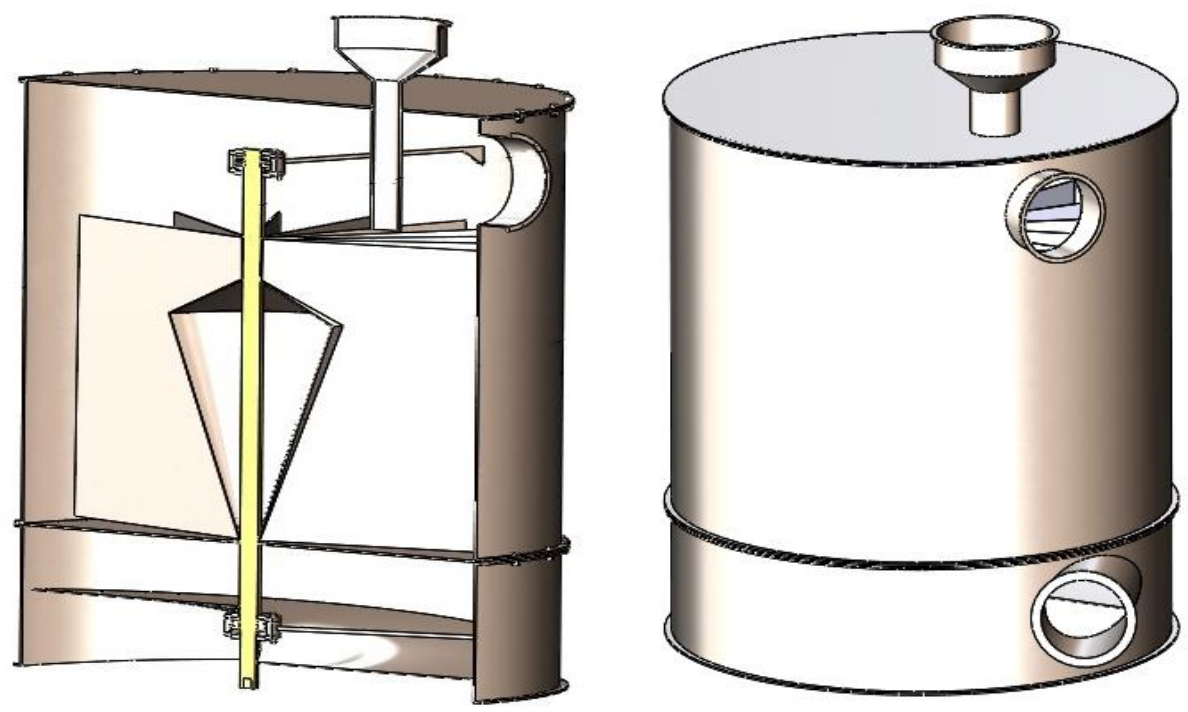

Figure 1. Improved drying chamber of rotary dryer with a fluidized bed
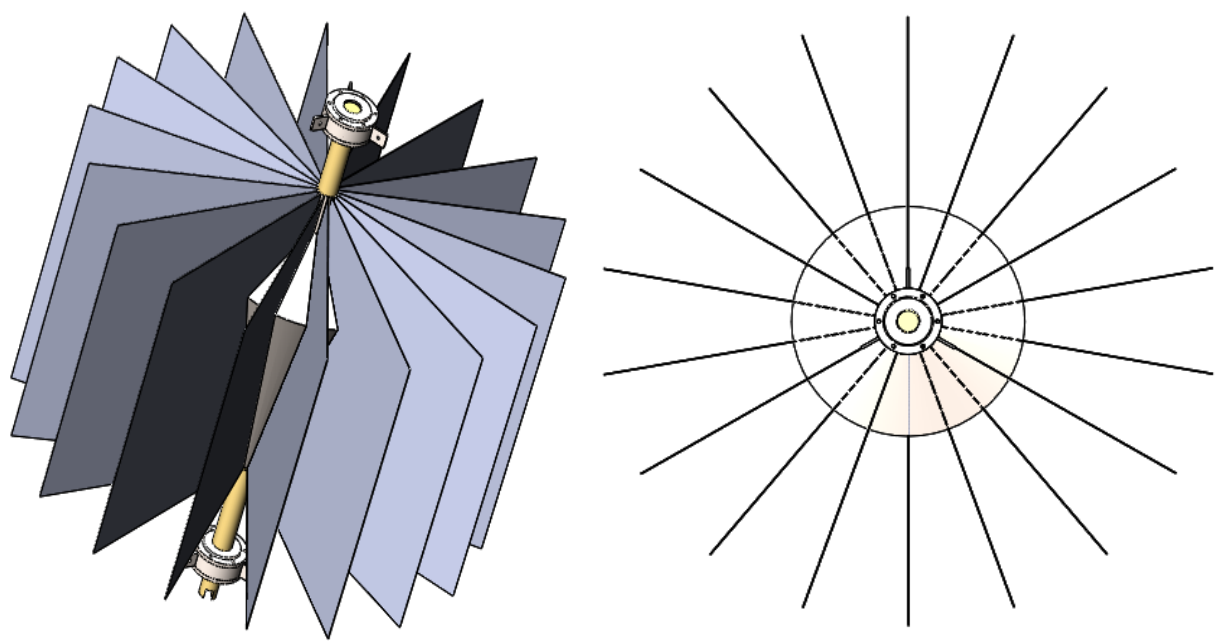

Figure 2. Model of the drive shaft with a conical element and blades 

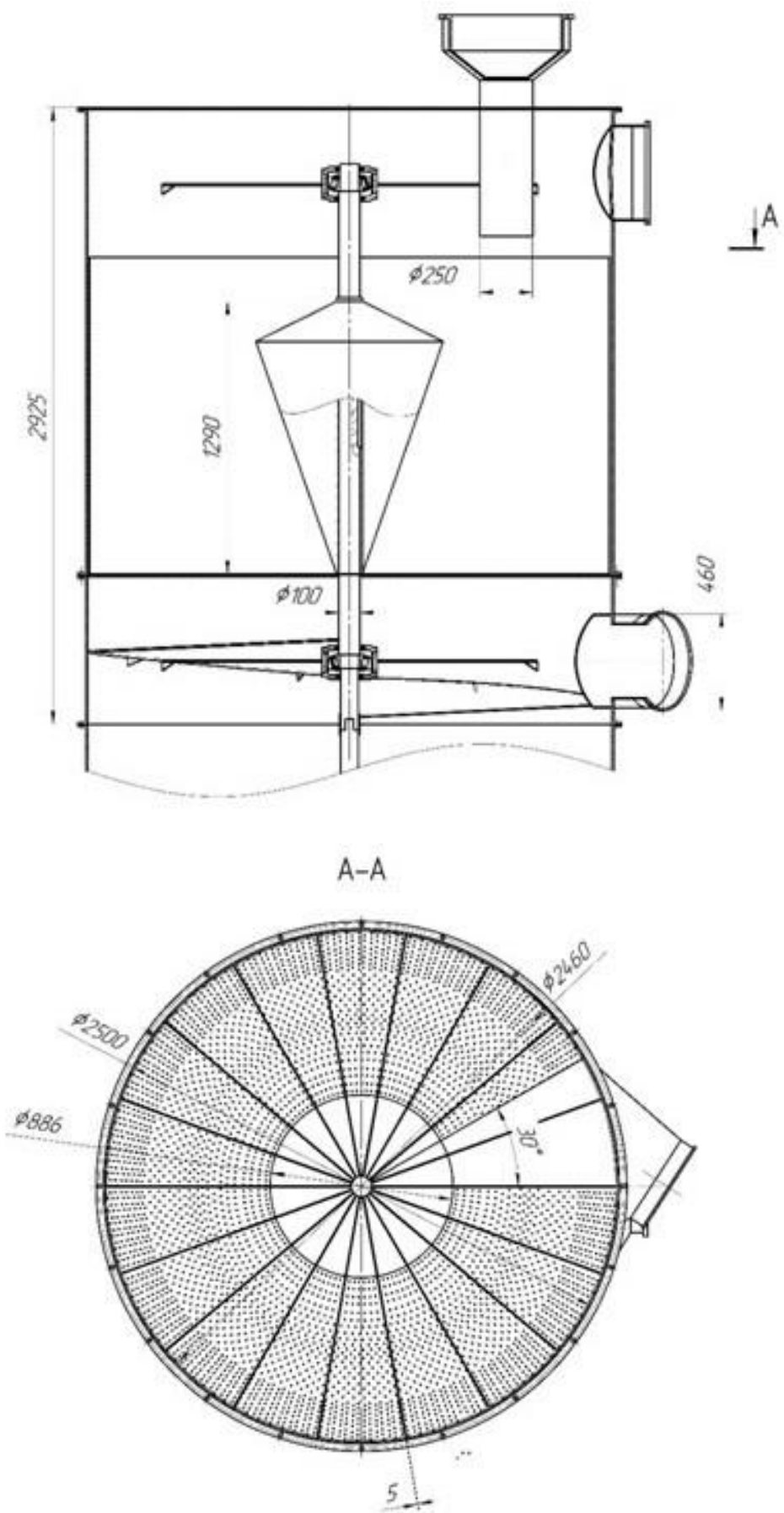

Figure 3. Geometric parameters of the model 
Modeling of drying agent flows was performed using the methods of Computational Fluid Dynamics (CFD), according to the method [16]. 3D models created in CAD Autodesk Inventor.

The following input parameters are entered into the model:

- initial temperature of the drying agent $-100^{\circ} \mathrm{C}$;

- final drying agent temperature $-55^{\circ} \mathrm{C}$;

- initial temperature of the material $-18^{\circ} \mathrm{C}$;

- final temperature of the material $-40{ }^{\circ} \mathrm{C}$;

- initial humidity of material $-25 \%$;

- final moisture content of the material - 14\%;

- initial relative humidity $-63 \%$;

- final relative humidity - $80 \%$;

- air velocity at the entrance to the material layer $-2 \mathrm{~m} / \mathrm{s}$;

- the average particle diameter of the material is $5 \mathrm{~mm}$.

The expected result of modeling the drying agent flows is finding the characteristic features of the gas-dynamic pattern in the drying chamber of this drying unit, to identify areas of intense vortex formation and separation in order to determine the rational parameters of the drying process.

\section{Description of the experimental dryer}

The simulation results were checked on an experimental plant (Figure 4).

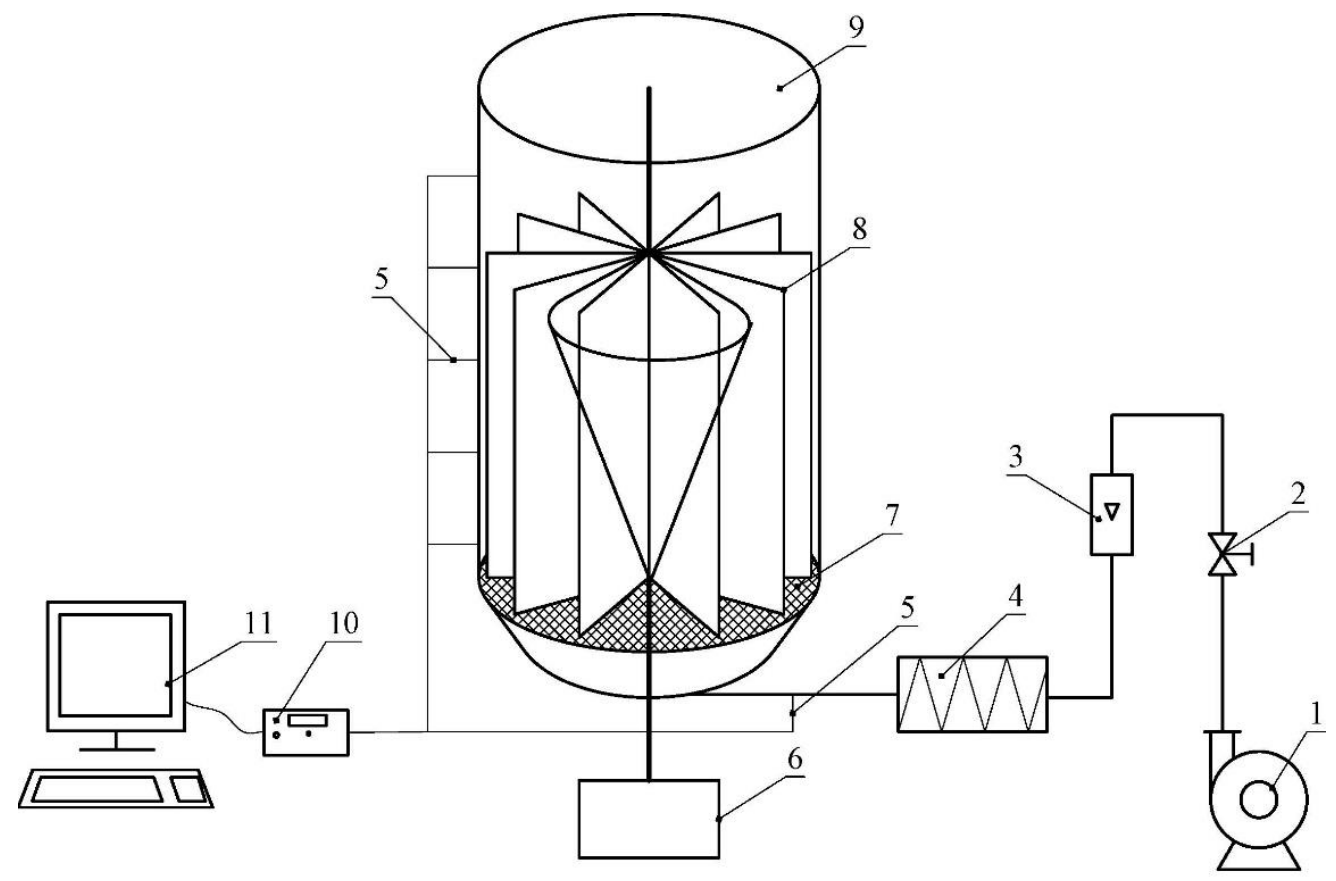

Figure 4. The scheme of the experimental plant for the drying peas research:

1 - blower; 2 - control valve; 3 - flow meter; 4 - heater; 5 - thermocouples;

6 - drive rotor of the device; 7 - gas distribution grille; 8 - rotor of the drying chamber;

9 - drying chamber; 10 - data logger; 11 - PC 
The input parameters of the heat carrier and product for experimental research were the same as for modeling.

The air is supplied by a blower 1 through the control valve 2 and the flow meter 3 to the heater 4 , where it is heated to $100{ }^{\circ} \mathrm{C}$ and enters the drying chamber 9 through the gas distribution grid 7 . The product is filled into the drying chamber 9 between the rotor blades 8. The temperature at the inlet and along the drying chamber is measured by thermocouples 5. The signals from the thermocouples are sent to the data logger 10 connected to the PC.

\section{Results and discussion}

As a result of researches graphs of distribution of speed, pressure and temperature of the heat carrier in the drying chamber are received.

According to [14], the minimum required heat carrier supply rate to create a stable fluidization regime when drying peas with an initial humidity of $23-25 \%$ is $1.8-2 \mathrm{~m} / \mathrm{s}$. It is discovered (Figure 5) that the velocity of the heat carrier in the drying chamber of the base unit [2] is according to the recommended limits only in the range from 0 to $0.7 \mathrm{~m}$ in the height of the chamber. The zone from 0.7 to $1.2 \mathrm{~m}$ is used less efficiently, because the velocity of the heat carrier is in the range of $1.65-1.8 \mathrm{~m} / \mathrm{s}$. The reason for this is that when the heat carrier passes through the wet product, its temperature decreases, which leads to a decrease in the volume of the heat carrier [18]. This causes the destruction of the constant mode of fluidization and, consequently, reduce the intensity of drying of the product. For a product with a higher initial humidity, this effect will be even much greater, as the minimum rate of fluidization increases linearly with the moisture content of the product [14].

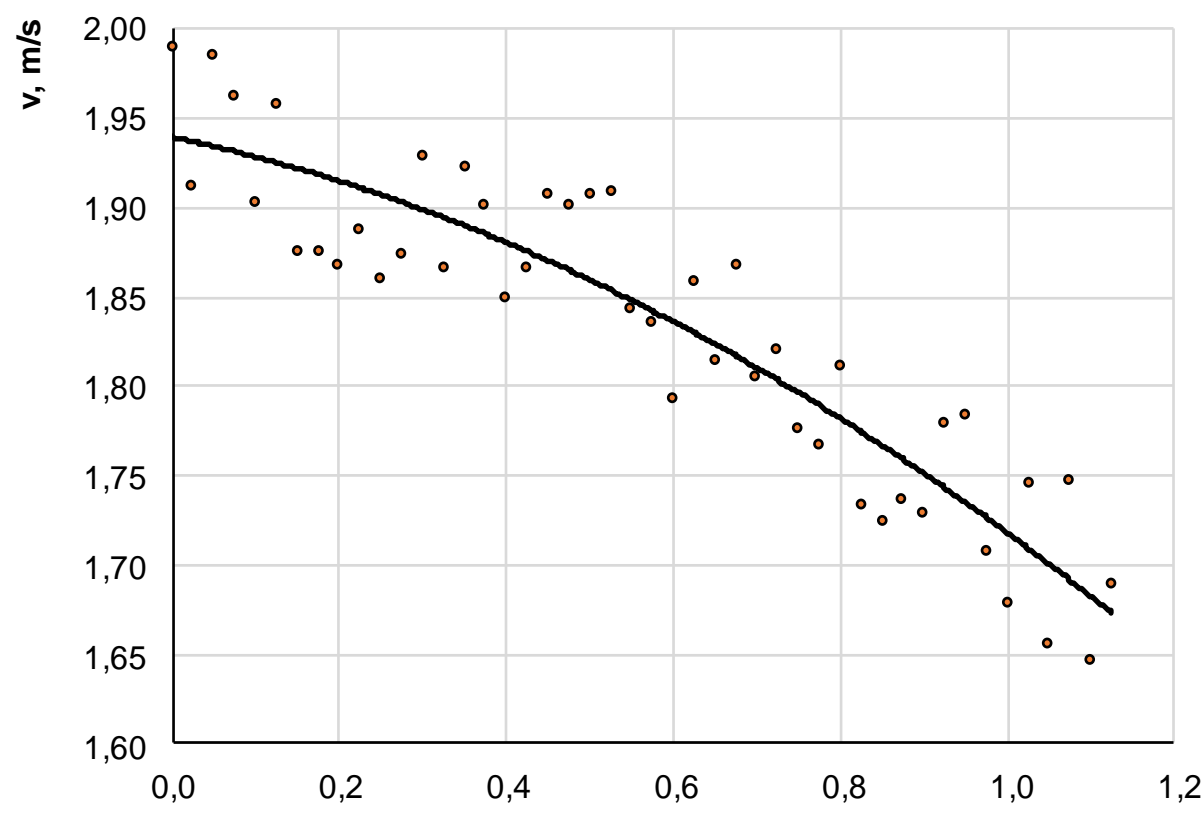

h, $\mathbf{m}$

Figure 5. Change of heat carrier velocity on the height of the drying chamber 
Investigating the change in heat carrier temperature along the height of the drying chamber depending on its initial speed (Figure 6), we found that when it grows above $2 \mathrm{~m} / \mathrm{s}$ there is a decrease in the efficiency of the drying agent potential. Thus, at the initial velocity of the heat carrier of $2 \mathrm{~m} / \mathrm{s}$ and the initial temperature of $100{ }^{\circ} \mathrm{C}$, its final temperature is about $55^{\circ} \mathrm{C}$, which corresponds to the accepted drying regulations for installations of this type. With increasing speed to 2.2 and $2.4 \mathrm{~m} / \mathrm{s}$, there is an increase in the final temperature of the heat carrier to 58 and $60{ }^{\circ} \mathrm{C}$. This is because the heat carrier does not have time to give the required amount of heat to the product at high speeds.

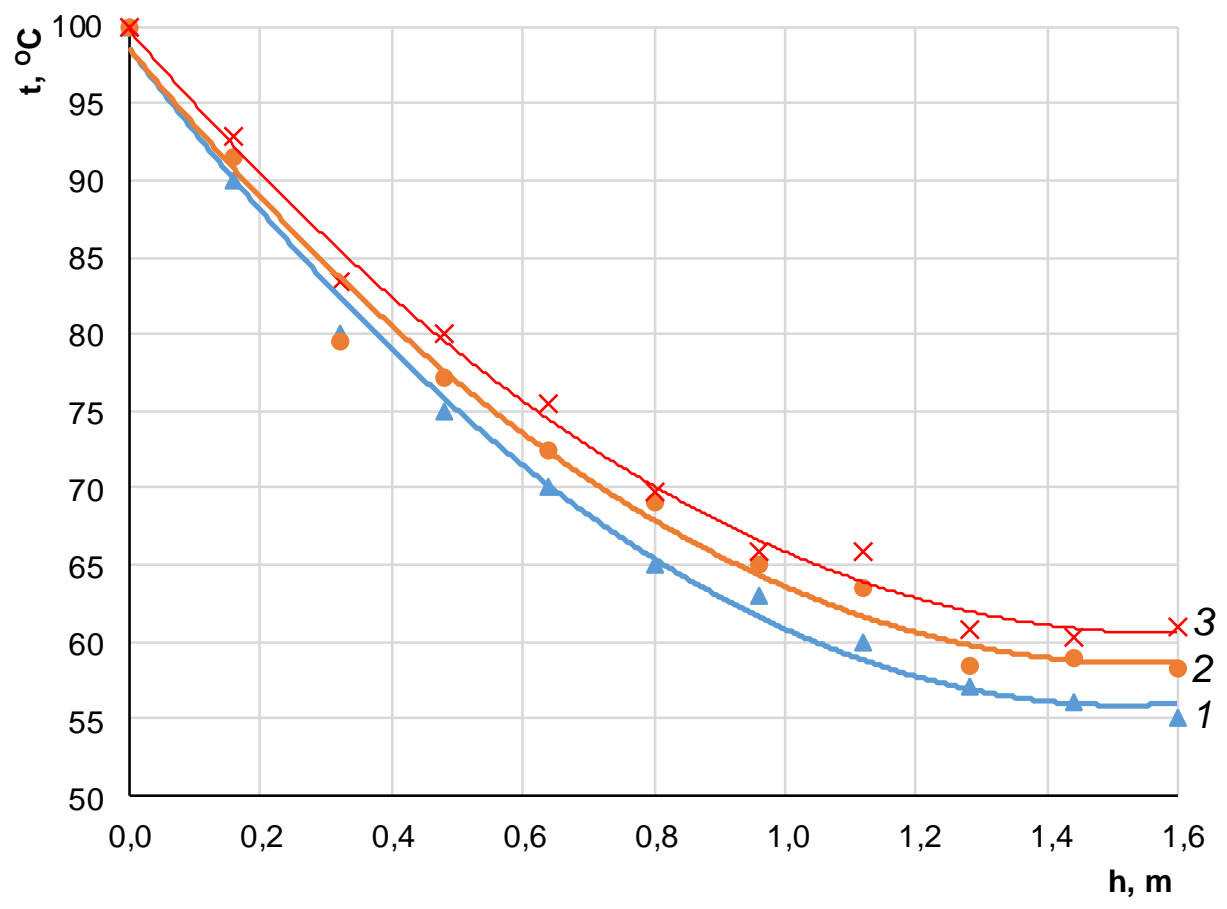

Figure 6. Change of heat carrier temperature on height of the drying chamber depending on its initial speed: $1-2 \mathrm{~m} / \mathrm{s} ; 2-2.2 \mathrm{~m} / \mathrm{s} ; 3-2.4 \mathrm{~m} / \mathrm{s}$.

Therefore, it is impossible to ensure a constant fluidization mode by increasing the inlet velocity of the heat carrier without reducing the efficiency of the drying unit. To ensure a uniform fluidization rate along the height of the chamber, a conical element with an expanded base at the top is installed, which gradually reduces the cross section of the drying chamber (Figure 1, 2, 3).

The positive effect of installing a conical element is as follows. As it was mentioned before, lowering the heat carrier temperature leads to a decrease in its volume. However, reducing the cross-sectional area where the heat carrier passes in the dryer with a conical element stabilizes its speed. As a result, the velocity of the heat carrier remains constant throughout the height of the fluidized bed, which creates conditions for higher drying intensity of the material and improves the quality of the dried product, because it cannot stay too long in the high temperature zone [18]. 
In addition, to detect the effect of the installation of a conical element on the pressure of the heat carrier flow, the change of this pressure along the height of the chamber was investigated. It is seen (Figure 7) that in the chamber of the basic dryer (without a conical element) there are fluctuations of this parameter in the range from 3350 to $3720 \mathrm{~Pa}$. There is a slight decrease of average pressure from 3565 to $3550 \mathrm{~Pa}$ from the beginning to the end of the zone of intensive drying.

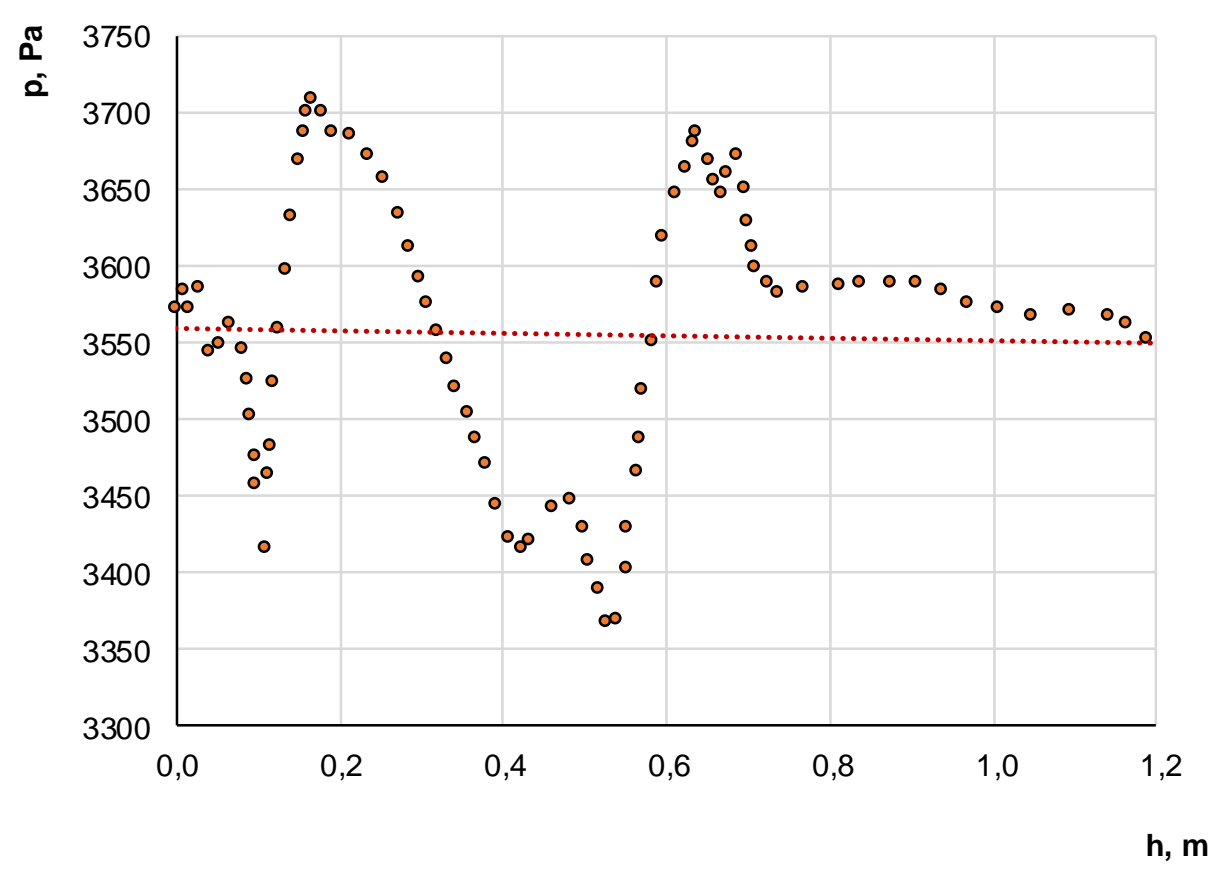

Figure 7. Change of drying agent pressure on the height of the drying chamber

For a more detailed picture of the pressure distribution of the heat carrier flows over the volume of the chamber, the results of research in the form of vector pressure fields are given (Figure 8).

The following results of similar researches are shown, but for a dryer with a conical element.

It is shown on the Figure 9. that in this kind of drying chamber the velocity of the heat carrier is according to the recommended $(1.8-2 \mathrm{~m} / \mathrm{s})$ limits along the entire height of the drying zone, which confirms the correct choice of design and geometric parameters of the conical element (Figure 3). 
Relative pressure, $\mathrm{Pa}$
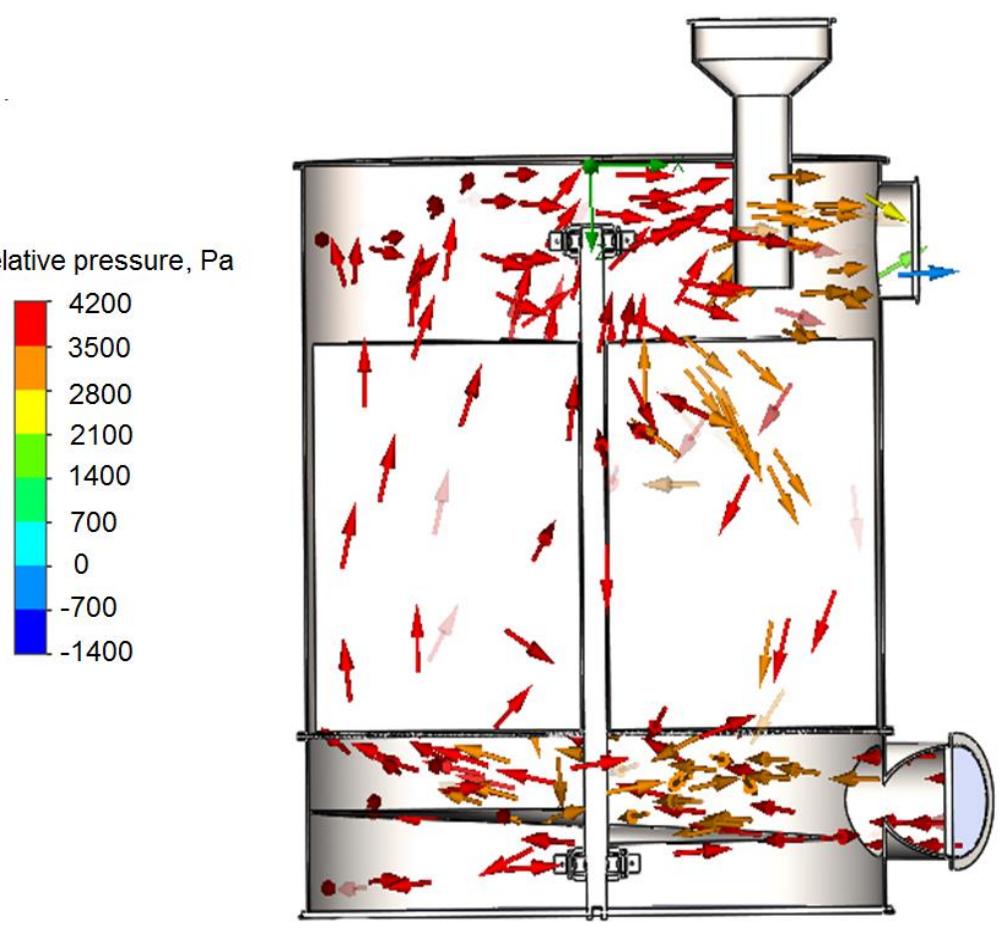

Figure 8. Vector pressure fields of the drying agent in the drying chamber

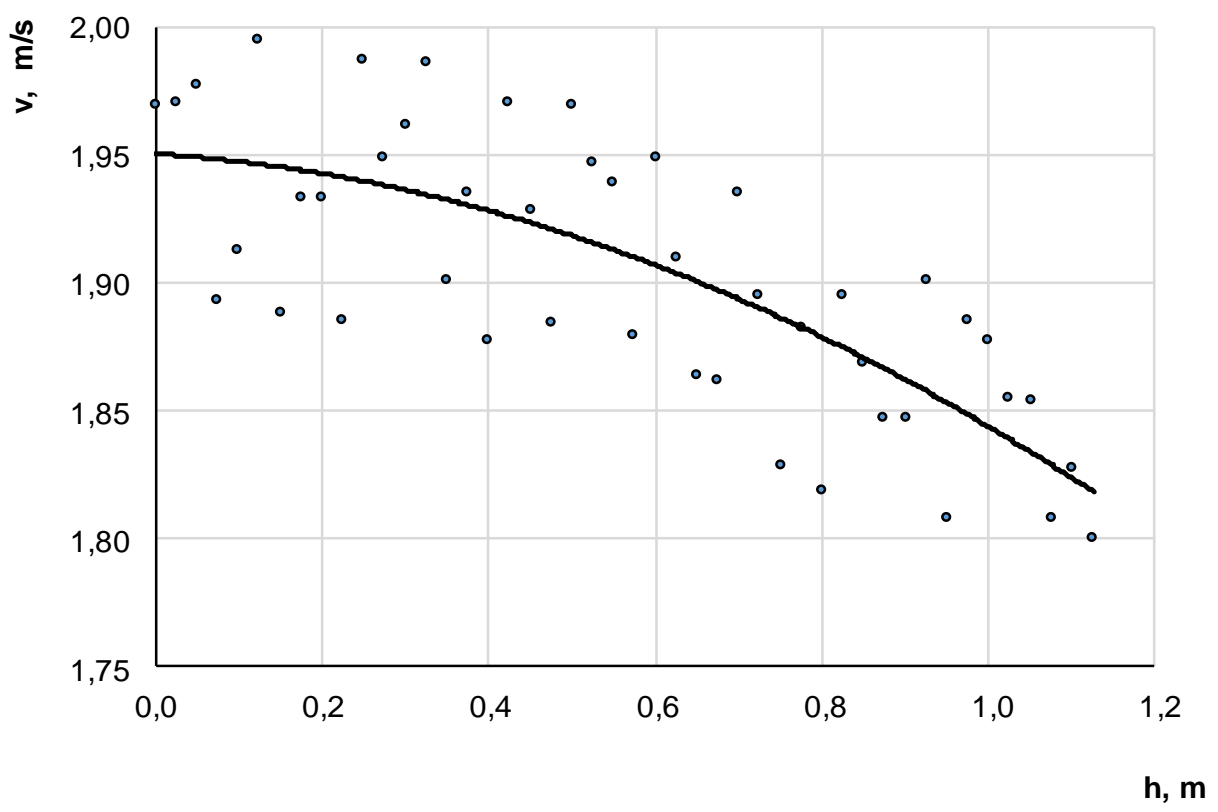

Figure 9. Change of the heat carrier speed on height of the drying chamber with a conic element 


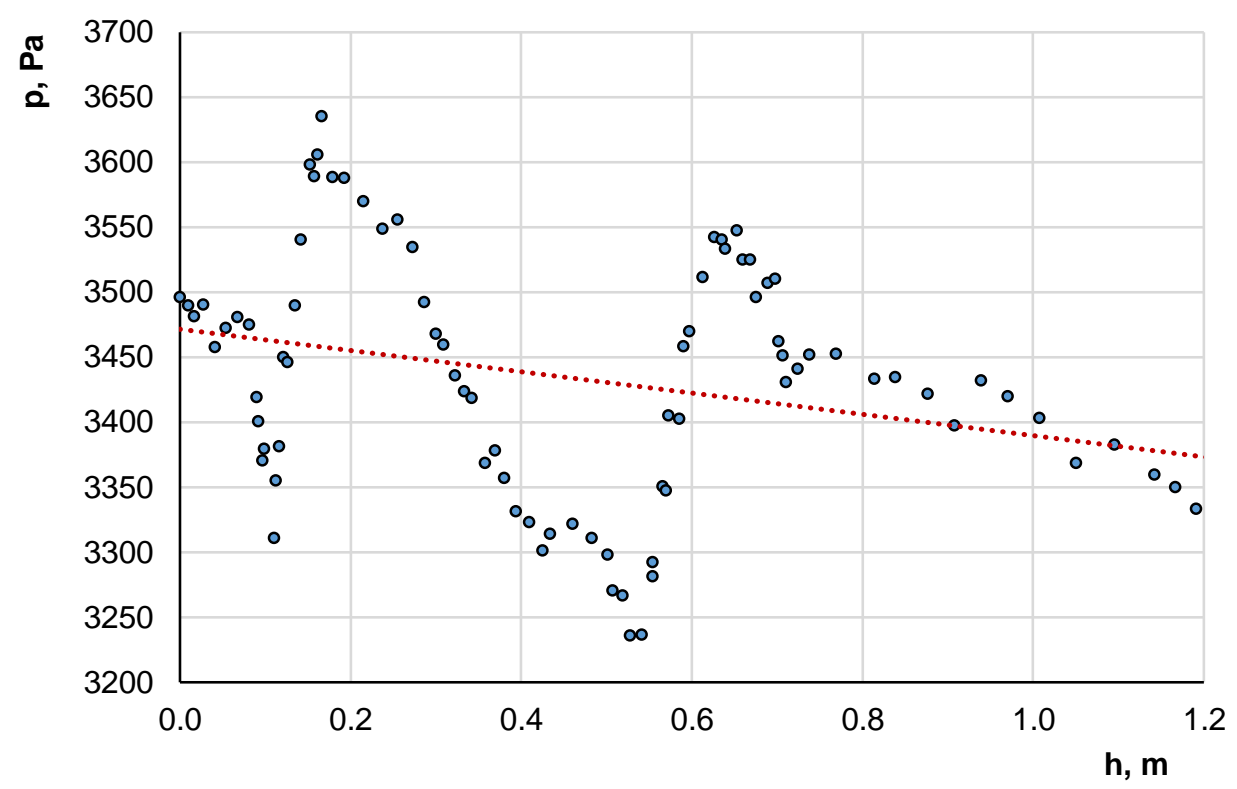

Figure 10. Change of the heat carrier pressure on height of the drying chamber with a conic element

In the chamber of the dryer with a conical element (Figure 10), the nature of the pressure change has changed slightly and there is a more pronounced decrease compared to the basic dryer. Pressure fluctuations are in the range from 3240 to $3630 \mathrm{~Pa}$. There is a slight decrease in the average pressure from 3475 to $3380 \mathrm{~Pa}$ from the beginning to the end of the drying zone. These changes are fully consistent with the laws of gas dynamics, because the speed of the heat carrier in the dryer with a conical element is slightly higher than in the basic one.

The results of research on the experimental plant confirm the data obtained by simulation.

From Figure 11, it is seen that the nature of the temperature change corresponds to the data obtained by simulation in the corresponding range of heights of the drying chamber. The error varies between 3-4\%. The nature of the change in the gas-dynamic parameters of the heat carrier is confirmed in researches $[14,17]$. 


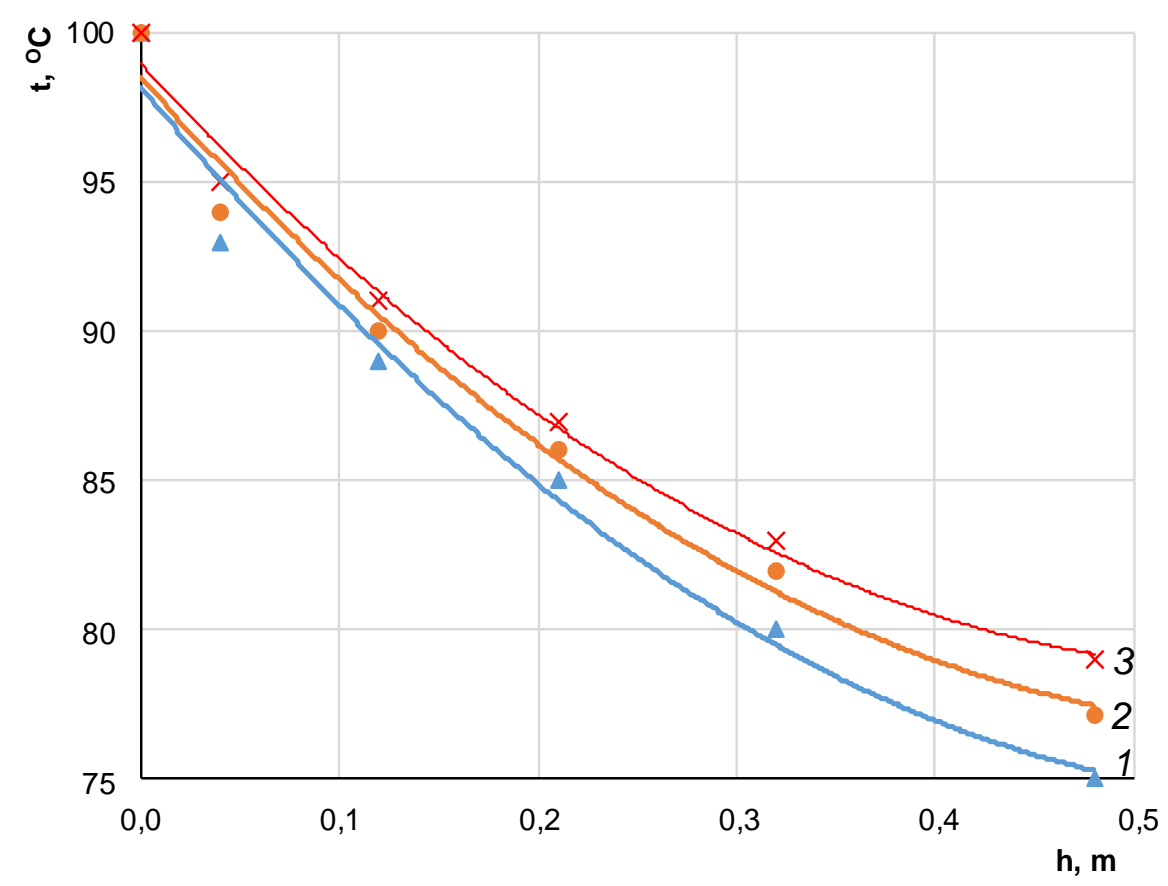

Figure 11. Change of the heat carrier temperature on the height of the drying chamber of the experimental plant depending on its initial speed:

$1-2 \mathrm{~m} / \mathrm{s} ; 2-2.2 \mathrm{~m} / \mathrm{s} ; 3-2.4 \mathrm{~m} / \mathrm{s}$

\section{Conclusions}

1. It is found out that the speed of the heat carrier in the drying chamber of the dryer without a conical element is in the recommended range $(1.8-2 \mathrm{~m} / \mathrm{s})$ only in the range from 0 to $0.7 \mathrm{~m}$ in the height of the chamber. The zone from 0.7 to $1.2 \mathrm{~m}$ is used less efficiently, because the velocity of the heat carrier is in the range of $1.65-1.8 \mathrm{~m} / \mathrm{s}$.

2. In the dryer with a conical element, the stabilization of the heat carrier velocity is achieved within the recommended $(1.8-2 \mathrm{~m} / \mathrm{s})$ limits along the entire height of the drying zone, which provides a constant height of the fluidized bed of product in the drying chamber. This creates the conditions for a higher intensity of drying the material and improves the quality of the dried product, because it does not stay for a long time in the high temperature zone.

3. It is discovered that when speed of the heat carrier increases over $2 \mathrm{~m} / \mathrm{s}$ efficiency decrease of use of its potential is observed. Thus, at an initial velocity of $2 \mathrm{~m} / \mathrm{s}$ and an initial temperature of $100{ }^{\circ} \mathrm{C}$, its final temperature is about $55^{\circ} \mathrm{C}$, which corresponds to the adopted drying regulations for installations of this type. With increasing speed to 2.2 and $2.4 \mathrm{~m} / \mathrm{s}$ there is an increase in the final temperature of the heat carrier to 58 and 60 ${ }^{\circ} \mathrm{C}$ what consequently reduces the efficiency of this dryer. 


\section{References}

1. Hatamipour M.S., Mowla D. (2007), Correlations for shrinkage, density and diffusivity for drying of maize and green peas in a fluidized bed with energy carrier, Journal of Food Engineering, 59(2-3), pp. 221-227.

2. Yakobchuk R. (2014), The influence of design parameters of rotary dryer on sunflower seeds drying, Ukrainian Food Journal, 3(3), pp. 437-445.

3. Scaar H., Franke G., Weigler F., Delele M.A., Tsotsas E., Mellmann J. (2016), Experimental and numerical study of the airflow distribution during mixed-flow grain drying, Drying Technology, 34(5), pp. 595-607.

4. Fabian Weigler, Jochen Mellmann (2014), Investigation of grain mass flow in a mixed flow dryer, Particuology, 12, pp. 33-39.

5. Mykhailyk V., Lementar S., Yakobchuk R., Skrynnyk Y., Semenko R. (2016), Wheat grain drying kinetics in a thin layer, Ukrainian Journal of Food Science, 4(2), pp. 316326.

6. Guo B., Langrish T.A.G., Fletcher D.F. (2003), Simulation of gas flow instability in a spray dryer, Trans IChemE, Part A, Chem Eng Res Des, 81, pp. 631-175.

7. Harvie D. J. E., Langrish T.A.G., Fletcher D.F. (2001), Numerical simulations of gas flow patterns within a tall-from spray dryer, Trans IChemE, Part A, Chem Eng Res Des,79, pp. 235-248.

8. Kota K., Langrish T. (2007), Prediction of Deposition Patterns in a Pilot-Scale Spray Dryer Using CFD Simulations, Chem. Prod. and Proc. Modeling, 2(3), pp. 26-35.

9. Silva, M. G., Lira, T. S., Arruda, E. B., Murata, V. V., \& Barrozo, M. A. S.. (2012). Modelling of fertilizer drying in a rotary dryer: parametric sensitivity analysis, Brazilian Journal of Chemical Engineering, 29(2), pp. 359-369.

10. Poós T., Szabó V. (2017), Application of mathematical models using volumetric transfer coefficients in fluidized bed dryers, Energy Procedia, 112, pp.374-381.

11. Arruda, E. B. (2008), Comparison of the performance of the roto-fluidized dryer and conventional rotary dryer. PhD. Thesis, Uberlândia-Brazil, Federal University of Uberlândia.

12. Ghalavand Y., Hatamipour M.S. \& Rahimi A. (2011), Kinetics Study of Green Peas Drying in a Spouted Bed in the Presence of a Heat Carrier, Drying Technology: An International Journal, 29, pp. 1648-1655.

13. Zhanyong Li, Jingsheng Ye, Hongtai Wang, Ruifang Wang (2006), Drying characteristics of green peas in fluidized beds, Transactions TSTU, 12(3A), pp. 668675.

14. Liu Y., Peng J., Kansha Y., Ishizuka M., Tsutsumi A., Jia D., Bi X.T., Lim C.J., Sokhansanj S., Novel fluidized bed dryer for biomass drying, Fuel Processing Technology, 122, pp. 170-175.

15. Lementar S., Ponomarenko V., Lulka D., Dubivko A. (2015), Modeling of the air supply system in spray dryer, Ukrainian Food Journal, 2(1), pp. 77-87.

16. Kaur, H. \& Bawa, Amarinder. (2002). Studies on fluidized bed drying of peas, Journal of Food Science and Technology - Mysore, 39, pp. 272-275.

17. Siddique A.B. and Wright D. (2003), Effects of Different Drying Time and Temperature on Moisture Percentage and Seed Quality (Viability and Vigour) of Pea Seeds (Pisum sativum L.), Asian Journal of Plant Sciences, 2, pp. 978-982. 